\title{
G-Protein-Coupled Receptor Cell Signaling Pathways Mediating Embryonic Chick Retinal Growth Cone Collapse Induced by Lysophosphatidic Acid and Sphingosine-1-Phosphate
}

\author{
Jarod Fincher Canaan Whiteneck Eric Birgbauer
}

Department of Biology, Winthrop University, Rock Hill, S.C., USA

\section{Key Words}

Retinal ganglion cells · Axon guidance · Chicken ·

Lysophosphatidic acid · Lpar

\begin{abstract}
In the development of the nervous system, one of the critical aspects is the proper navigation of axons to their targets, i.e. the problem of axonal guidance. We used the chick visual system as a model to investigate the role of the lysophospholipids lysophosphatidic acid (LPA) and sphingosine1-phosphate (S1P) as potential axon guidance cues. We showed that both LPA and S1P cause a specific, dose-dependent growth cone collapse of retinal neurons in vitro in the chick model system, with slight differences compared to the mouse but very similar to observations in Xenopus. Because LPA and S1P receptors are G-protein-coupled receptors, we analyzed the intracellular signaling pathways using pharmacological inhibitors in chick retinal neurons. Blocking rho kinase (ROCK) prevented growth cone collapse by LPA and S1P, while blocking PLC or chelating calcium had no effect on growth cone collapse. Inhibition of $\mathrm{G}_{\mathrm{i} / \mathrm{o}}$ with pertussis toxin resulted in a partial reduction of growth cone collapse, both with LPA and with S1P. Inhibition of p38 blocked
\end{abstract}

\section{KARGER}

(c) 2014 S. Karger AG, Basel

0378-5866/14/0366-0443\$39.50/0

E-Mail karger@karger.com

www.karger.com/dne growth cone collapse mediated by LPA but not S1P. Thus, in addition to the involvement of the $\mathrm{G}_{12 / 13}$-ROCK pathway, LPA- and S1P-induced collapse of chick retinal growth cones has a partial requirement for $\mathrm{G}_{\mathrm{i} / \mathrm{o}}$.

(c) 2014 S. Karger AG, Basel

\section{Introduction}

One important aspect of development in the nervous system is the problem of axon guidance. The visual system is an excellent system for the investigation of axonal guidance. There is a well-studied stereotypical pathway from the retina to targets in the brain, which includes several intermediate guidance points as well as final mapping to the target, with the formation of a topographic map. Furthermore, there is only one type of output neuron from the retina: the retinal ganglion cells (RGCs), whose axons navigate relatively long distances to their final target in the brain.

\section{J. Fincher and C. Whiteneck contributed equally to this work.}


The molecular mechanism of axon guidance involves cues along the pathway that interact with receptors on the navigating axonal growth cone. Many protein guidance cues and their corresponding receptors, including Ephs and ephrins [1], netrin [2,3], slits [4-7], and semaphorins $[8,9]$, have been demonstrated to play important roles in the visual system. However, to date, the major axon guidance cues identified have been proteins. We are investigating a novel set of biologically active molecules, i.e. signaling lysophospholipids and specifically lysophosphatidic acid (LPA) and sphingosine-1-phosphate (S1P), as potential axon guidance cues. Similar to well-documented, inhibitory guidance cues, LPA and S1P have been shown to cause growth cone collapse in culture in a variety of neuronal cell lines [10-15] and some primary neurons [16-18], including mouse and Xenopus retinal axons [19-22]. Furthermore, there is evidence in Xenopus that S1P may be involved in correct pathfinding into the tectum [22]. Thus, we investigated their role in the chick visual system.

The lysophospholipids LPA and S1P mediate extracellular signaling by binding to cell surface receptors of the G-protein coupled receptor (GPCR) family [23, 24]. There are at least 5 high-affinity LPA receptors, i.e. $\mathrm{LPA}_{1}$ to $\mathrm{LPA}_{5}$, and $5 \mathrm{~S} 1 \mathrm{P}$ receptors, i.e. $\mathrm{S}_{1} \mathrm{P}_{1}$ to $\mathrm{S} 1 \mathrm{P}_{5}[25$, 26 , with additional reports of other potential receptors [27-30]. Ligand binding to these receptors has been shown to activate classic intracellular signaling through G protein pathways, including $\mathrm{G}_{\mathrm{i} / \mathrm{o}}, \mathrm{G}_{\mathrm{q}}, \mathrm{G}_{12 / 13}$, and possibly $\mathrm{G}_{\mathrm{s}}$.

In this study, we examined the responses of retinal growth cones to LPA and S1P and the intracellular signaling pathways mediating these responses in the model system of the embryonic chick. The chick has several advantages, including being well studied, having large, early developing eyes, and all stages of embryonic development easily accessible. We compared the responses in chickens to previous reports in mice and Xenopus.

\section{Materials and Methods}

\section{Chick Retinal Culture}

Retinas were dissected from embryonic day 6 (E6) chicken embryos (Hamburger and Hamilton stages 28-29) and cut into explants. Explants were cultured in Ham's F12 media (Hyclone) supplemented with N2 and B27 (Life Technologies), 1 mM sodium pyruvate, $0.5 \mathrm{mg} / \mathrm{ml}$ ascorbic acid, $10 \mathrm{ng} / \mathrm{ml}$ CNTF (PeproTech), $50 \mathrm{ng} / \mathrm{ml} \mathrm{BDNF}$ (PeproTech), and penicillin-streptomycin in a $37^{\circ} \mathrm{C}, 5 \% \mathrm{CO}_{2}$ incubator. After overnight incubation on $0.1 \mathrm{mg} /$ $\mathrm{ml}$ poly-D-lysine and $10 \mu \mathrm{g} / \mathrm{ml}$ laminin-coated dishes, cultures were treated as described below.

\section{Growth Cone Collapse Assay}

Retinal explants were cultured overnight as described above in Nunc Lab-Tek 4-well chambered coverglass dishes. LPA (18:1 oleoyl; Avanti Polar Lipids) lyophilized aliquots were dissolved in water and then a $1 \mathrm{~mm}$ stock in PBS with $10 \%$ fatty acid-free BSA (Sigma) was made which was diluted with media (above) to form final concentrations. S1P (BioMol/Enzo Life Sciences) lyophilized aliquots were dissolved in water containing $4 \mathrm{mg} / \mathrm{ml}$ fatty acid-free BSA (Sigma) to form a $100 \mu \mathrm{M}$ stock which was diluted with media to form final concentrations. Controls were made by diluting the carrier solution without lysophospholipids into media at similar dilutions. For treatment, one third of the volume of culture media was removed from each well and one third of the volume of media containing controls or lysophospholipids was added to each well, incubated for $10 \mathrm{~min}$ in a $37^{\circ} \mathrm{C}, 5 \% \mathrm{CO}_{2}$ incubator, and then fixed by carefully underlaying cultures with $4 \%$ paraformaldehyde in $0.1 \mathrm{M}$ phosphate buffer ( $\mathrm{pH}$ 7.4). After fixation, cultures were permeabilized with $0.1 \%$ Triton X-100 in PBS and stained with Alexa Fluor 488 phalloidin (Life Technologies) and examined on an Olympus CKX41 fluorescence microscope. To quantify growth cone collapse, isolated growth cones not touching other neurites or growth cones but attached to neurites emanating from the explant were categorized as 'normal' or 'collapsed' and counted, and the percent collapsed was calculated. A growth cone was categorized as collapsed if there was no lamellipodia and 1 or possibly up to 3 extensions parallel to the axon; these extensions appeared to be retraction fibers based on their morphology (thinner at the tip), although we could not rule out that they were filopodia. If a growth cone could not be unambiguously determined to be collapsed or not, it was excluded from the analysis; less than $5 \%$ of all growth cones in any experiment or condition were omitted by this criteria. To confirm the lack of bias, a subset of data was independently verified by another investigator (E.B.). Statistical analysis was performed using Fisher's exact test (GraphPad Prism).

To test specificity, other lysophospholipids were obtained from Avanti Polar Lipids and used as described for LPA above: 14:0 (stearoyl) LPA, 18:0 (myristoyl) LPA, 18:1 dioleoylglycerol pyrophosphate (DGPP), C18:1 lyso PAF (1-O-oleyl-sn-glycero3-phosphocholine), and egg lysophosphatidylcholine (LPC).

\section{Time-Lapse Imaging}

Retinal explants were prepared as above and grown overnight on MatTek glass bottom dishes (poly-D-lysine and laminin coated). The dishes were placed in a stage top incubator chamber (Warner Instruments) at $37^{\circ} \mathrm{C}$ with $\mathrm{CO}_{2}$ and images were taken every $30 \mathrm{~s}$ with a Nikon D7000 DSLR camera using Micro-Manager (http://www.micro-manager.org) with ImageJ and NKRemote (Breeze Systems) software and a $\times 20$ objective with phase optics on a Nikon Diaphot microscope. Growth cones were imaged for 30-40 min to determine the baseline growth, and control medium was added to the dish and growth cones were imaged for another 30-40 min. Then, medium containing lysophospholipids was added to give the final concentration, and growth cones were imaged for another $30 \mathrm{~min}$ or until no growth cones were visible in the field, whichever occurred first.

\section{Inhibition of Cell Signaling Pathways}

Analysis of the inhibition of cell signaling pathways was performed as a growth cone collapse assay as described above, except that a $6 \times$ final concentration of pharmacological inhibitor (diluted 
Table 1. Primer sequences used for RT-PCR of chicken RNA

\begin{tabular}{lll}
\hline Target & Forward primer & Reverse primer \\
\hline lpar1 & CTATAGTGACTCCTACCTGGTC & AGGATCTGCTTGAAGGTAGC \\
lpar2 & TCAAGACGGTCACCATCATCC & GGGGTATATTTGGGGTTCC \\
lpar3 & CACTAGTGGATCTATAAGC & TCATAACAGAGTTCAGCAG \\
lpar4 & TGGAACTGGAGAGGGCTGAA & GGTGTGCTTCCGAAGGATGTC \\
lpar5 & GAAACGATCAGACAACAAGC & ACGGCCAGATTGAACATGTAG \\
p $2 y 5$ & TGACTGCGGTCAGGACTATG & GTAACCGAGGCTGAAACCAA \\
GAPDH & CCTCTCTGGCAAAGTCCAAG & TGGCTGTCACCATTGAAGTC \\
\hline
\end{tabular}

from stock into media) was added prior to the addition of the $6 \times$ final concentration of LPA or S1P (and remained present during lysophospholipid addition). Controls included carrier for inhibitor along with LPA and S1P and also inhibitor without LPA or S1P. Inhibitors were used at the final concentrations of: Y-27632, $10 \mu \mathrm{M}$; H1152, 100 nM; U-73122, $1 \mu \mathrm{M}$; BAPTA, $50 \mu \mathrm{M}$; SB 203580, $20 \mu \mathrm{M}$; PD 98059, $20 \mu \mathrm{M}$, and pertussis toxin (PTX), $200 \mathrm{ng} / \mathrm{ml}$. All inhibitors were added 10 min prior to LPA or S1P addition, except for PTX which was added $16-20 \mathrm{~h}$ prior to allow sufficient time for PTX, an enzyme, to cross the cell membrane and then catalytically ADP-ribosylate $G_{i}[31-34]$. All inhibitors were obtained from Calbiochem, except for PTX (List Biological Laboratories). Note that the data are from at least 3 independent experiments (except 2 for BAPTA with LPA) and at least 125 growth cones were analyzed for each treatment condition (data on the number of experiments and the number of growth cones analyzed is presented in online suppl. table 1; for all online suppl. material, see www.karger.com/ doi/10.1159/000364858). Note that the PTX data was collected by 2 investigators (J.F. and C.W.), and a subset of the growth cone counts was verified independently by a third investigator (E.B.). Statistical analysis by Fisher's exact test was performed comparing inhibitor plus lysophospholipid to inhibitor without lysophospholipid and comparing treatment with inhibitor to treatment without inhibitor.

\section{RT-PCR Expression Analysis}

Total RNA from E6 chicken brain and retina was isolated with Trizol (Invitrogen) according to the manufacturer's protocol. RTPCR was performed using Qiagen's One-Step RT-PCR Kit as follows: RT for $30 \mathrm{~min}$ at $50^{\circ} \mathrm{C}$, followed by $15 \mathrm{~min}$ at $95^{\circ} \mathrm{C}$, and then 35 cycles of PCR at $94^{\circ} \mathrm{C}$ for $30 \mathrm{~s}, 55^{\circ} \mathrm{C}$ for $1 \mathrm{~min}, 72^{\circ} \mathrm{C}$ for $1 \mathrm{~min}$, and a final extension at $72^{\circ} \mathrm{C}$ for $10 \mathrm{~min}$. Products were electrophoresed on a $1.5 \%$ agarose gel containing ethidium bromide and imaged on a UV transilluminator system (BioRad). The primers used for RT-PCR are given in table 1.

\section{Results}

\section{LPA and S1P Cause Growth Cone Collapse of \\ Embryonic Chick Retinal Neurons}

We first established the response of embryonic chicken retinal growth cones to the signaling lysophospholipids LPA and S1P. Treatment with LPA added uniformly to the media resulted in a rapid growth cone collapse gen- erally followed by neurite retraction (fig. 1a). This growth cone collapse occurred on average $2.4 \mathrm{~min}( \pm 0.86 ; \mathrm{n}=18)$ after the addition of $1 \mu \mathrm{M} \mathrm{LPA}$ or an average of $4.5 \mathrm{~min}$ $( \pm 5.3 ; \mathrm{n}=37)$ after the addition of $100 \mathrm{nM} \mathrm{LPA}$. Similarly, on embryonic chick retinal growth cones, S1P treatment also produced a rapid growth cone collapse, again usually followed by neurite retraction (fig. 1b). This response to S1P occurred on average $2.2 \min ( \pm 0.60 ; n=21)$ after the addition of $1 \mu \mathrm{M} \mathrm{S1P}$.

This growth cone collapse response was analyzed quantitatively via a growth cone collapse assay measuring the number of growth cones showing a collapsed morphology (fig. 2c, d) compared to a normal-growth morphology (fig. 2a, b). Under culture conditions with just media addition, approximately $20 \%$ of embryonic chick retinal growth cones showed a collapsed morphology (control; fig. 2e). However, the addition of LPA caused a significant increase in collapsed growth cones, i.e. about $60 \%$ at $1 \mu \mathrm{M}$ (fig. 2e). This growth cone collapse response was dose dependent, with virtually no growth cone collapse at less than $10 \mathrm{nM}$; it was statistically significant $(\mathrm{p}<0.0001)$ at $10 \mathrm{nM} \mathrm{LPA}$ and above. The growth cone collapse began to plateau at around $1 \mu$ M LPA (fig. 2e). S1P also showed a similar dose-dependent growth cone collapse in embryonic chick retinal growth cones, with a statistically significant growth cone collapse at $10 \mathrm{nM}$ and above ( $\mathrm{p}<0.001$; fig. $2 \mathrm{e}$ ).

To confirm that the growth cone collapse response to LPA and S1P was specific and not a generalized lipid response, we examined the effect of other lipids (fig. 3). The longer-chain-length LPA (both 18:1 and the saturated 18: $0)$ produced growth cone collapse. The shorter-chainlength LPA (14:0) showed a reduced growth cone collapse, indicating chain length specificity. Again, S1P caused growth cone collapse. However, the other lipids tested, i.e. LPC, PAF, and DGPP, showed no or minimal growth cone collapse compared to controls. Thus, LPA and S1P cause a dose-dependent, specific growth cone collapse of embryonic chick retinal neurons. 

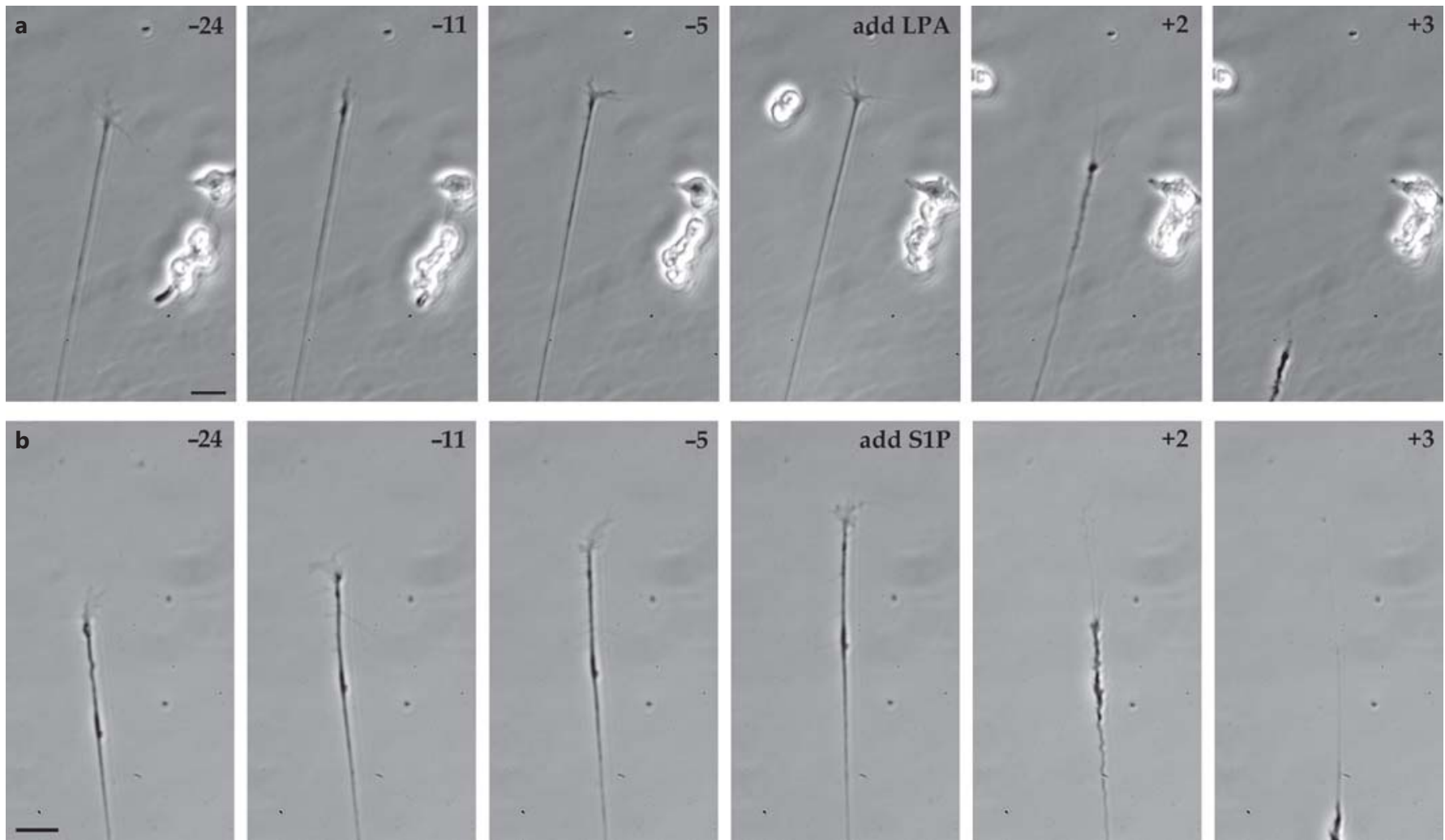

Fig. 1. Time-lapse imaging of growth cones from E6 chick retinal explants before (negative numbers) and after (positive numbers) the addition of $1 \mu \mathrm{M}$ LPA (a) or $1 \mu \mathrm{M} \mathrm{S1P}$ (b). The time is in minutes. Scale bars $=20 \mu \mathrm{m}$.
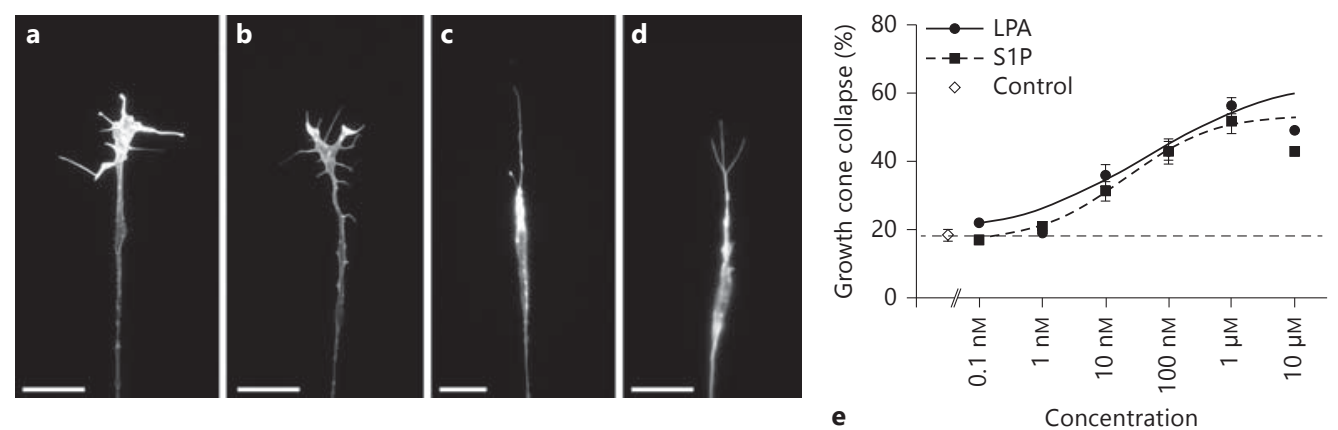

Fig. 2. Growth cone collapse after LPA and S1P treatment. a, b Examples of retinal growth cones showing a normal morphology under control conditions. Examples of retinal growth cones showing a collapsed morphology after treatment with $1 \mu \mathrm{M}$ LPA (c) or

\section{GPCR Signaling Pathways Activated in Growth Cone Collapse}

The lysophospholipids LPA and S1P have been shown to act by binding to extracellular receptors. There are several LPA and S1P receptors which are GPCRs and signal
$1 \mu \mathrm{M}$ S1P $(\mathbf{d})$. Scale bars $=20 \mu \mathrm{m}$. e Dose response of growth cone collapse with different concentrations of LPA and S1P compared to the control (no lipid) on a log scale. Error bars are SEM. The dashed line indicates the level of the control for reference. 


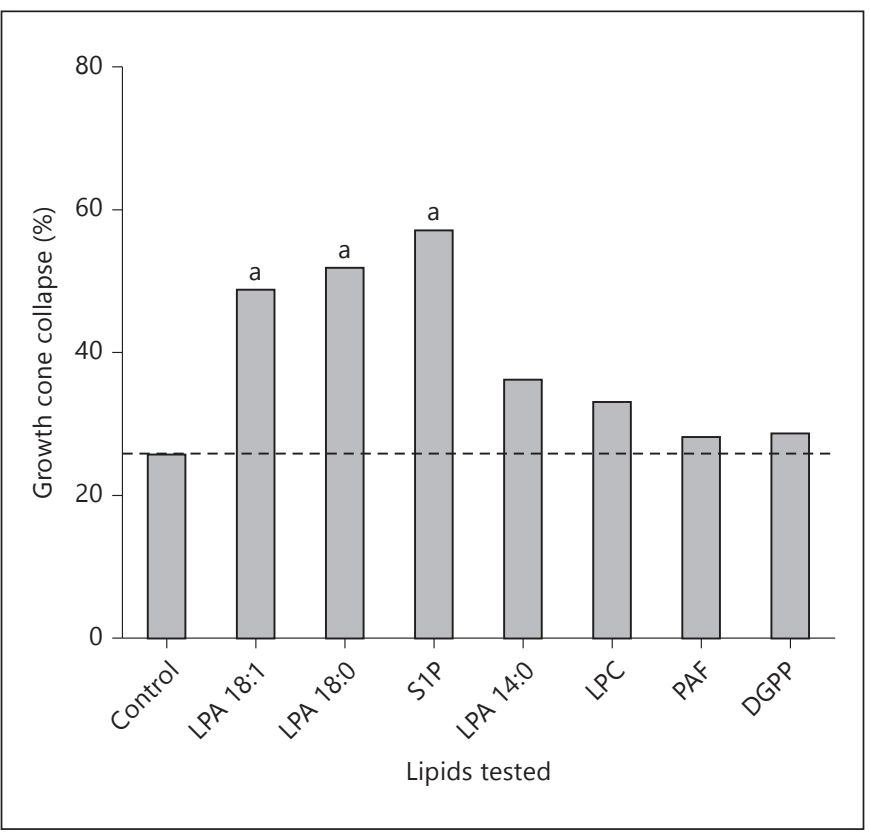

Fig. 3. Growth cone collapse response induced by different lipids. Chick retinal growth cone collapse induced by $1 \mu \mathrm{M}$ concentrations of various lipids compared to the control. ${ }^{a} \mathrm{p}<0.05$ compared to the control (Fisher's exact test). The dashed line indicates the level of the control for reference.

the growth cone collapse of embryonic chicken retinal neurons, we used established pharmacological inhibitors to block these pathways and then assayed for LPA- or S1P-induced growth cone collapse.

Previous studies in cell lines $[11,35]$ have shown that LPA causes growth cone collapse through the $\mathrm{G}_{12 / 13}$ pathway and the downstream effectors rho and rho kinase (ROCK). Thus, we verified the involvement of the $\mathrm{G}_{12 / 13}$ pathway in embryonic chicken retinal neurons using 2 different ROCK inhibitors, i.e. Y-27632 and H1152, both with similar results (fig. 4). Treatment with control media, or the ROCK inhibitors alone, showed a baseline growth cone collapse. Again, treatment with LPA or S1P produced a significant growth cone collapse above this baseline $(\mathrm{p}<0.0001)$. However, the addition of Y-27632 or H1152 prevented this LPA- or S1P-induced growth cone collapse, with collapse rates not significantly different from those of the control ( $\mathrm{p}=0.3-0.8)$. Thus, the $\mathrm{G}_{12 / 13}$-rho-ROCK pathway is required for the mediation of chick retinal growth cone collapse by LPA and S1P.

Another signaling pathway activated by GPCRs is $\mathrm{G}_{\mathrm{q}}$, which activates phospholipase C (PLC) and calcium release. We probed the $\mathrm{G}_{\mathrm{q}}$ pathway by blocking PLC or che-

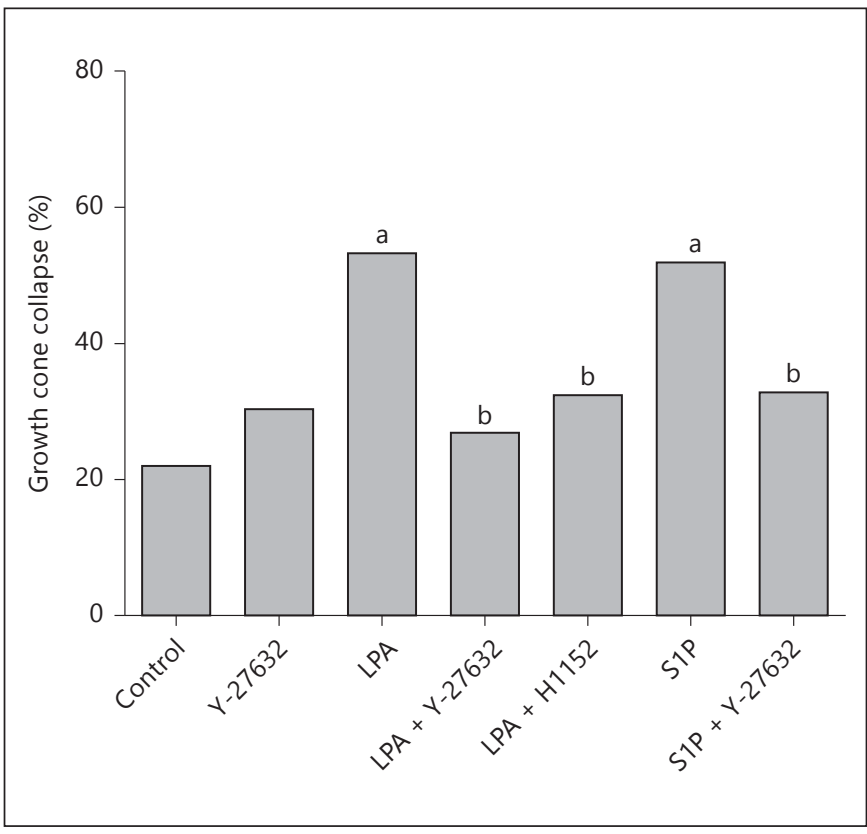

Fig. 4. Growth cone collapse blocked by ROCK inhibitors. Retinal growth cone collapse induced by $1 \mu \mathrm{M} \mathrm{LPA}$ or S1P is prevented by the presence of Y-27632 or H1152 compared to the control (without inhibitor) or Y-27632 alone. ${ }^{\mathrm{a}} \mathrm{p}<0.0001$ compared to the control; ${ }^{b} \mathrm{p}<0.0001$ compared to treatment with LPA or S1P without inhibitor.

lating calcium. When we blocked PLC with the inhibitor U-73122, there was still a significant growth cone collapse upon addition of LPA or S1P ( $p<0.0001$ vs. control; fig. 5). Furthermore, treatment with BAPTA to chelate calcium before the addition of LPA or S1P also did not change the significant growth cone collapse $(p<0.0001)$, which was similar to that with LPA or S1P alone. Thus, blocking PLC or calcium release downstream of $\mathrm{G}_{\mathrm{q}}$ had no effect on LPA- or S1P-induced growth cone collapse, suggesting that the $G_{q}$ pathway is not required for the LPA- or S1P-mediated growth cone collapse of embryonic chick retinal neurons.

A GPCR can also signal through $\mathrm{G}_{\mathrm{i} / \mathrm{o}}$, which includes the activation of rac for cytoskeletal regulation. PTX is an irreversible inhibitor of $\mathrm{G}_{\mathrm{i} / \mathrm{o}}$ (ADP-ribosylating $\mathrm{G}_{\mathrm{i} / \mathrm{o}}$ ) [3134]. Pretreatment with PTX prior to LPA or S1P treatment significantly reduced the growth cone collapse induced by these lysophospholipids ( $\mathrm{p}<0.0001$; fig. 6). However, there was still some growth cone collapse, significantly different from controls (for LPA: $\mathrm{p}<0.001$ ). Thus, in the presence of PTX, LPA and S1P can still induce some growth cone collapse of embryonic chick retinal neurites, but it is reduced compared to the collapse 


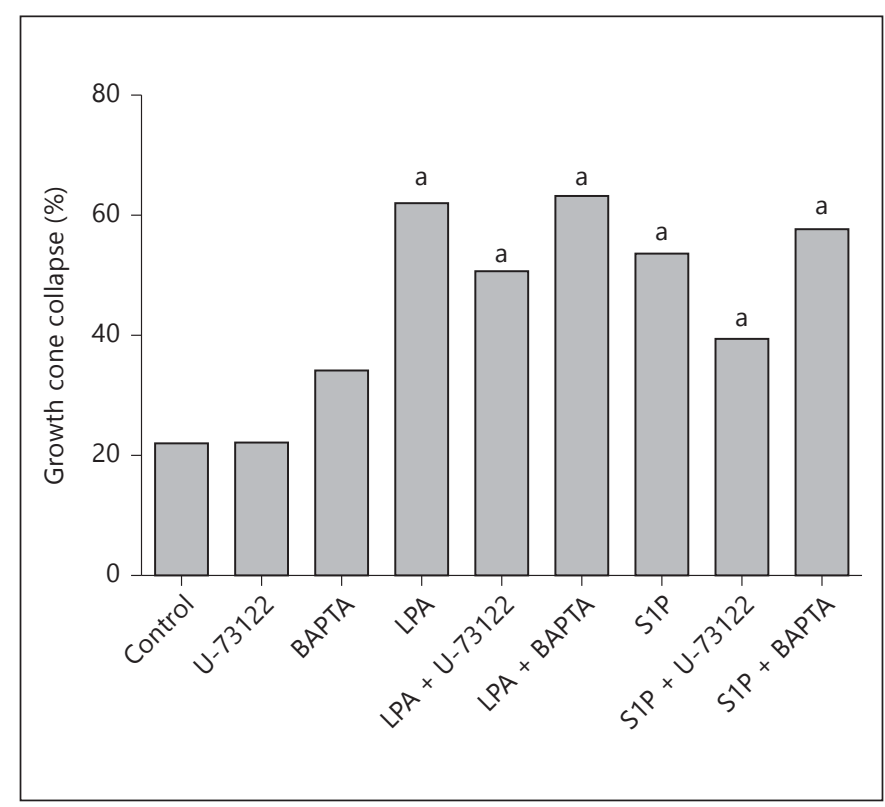

Fig. 5. Growth cone collapse after blocking the $\mathrm{G}_{\mathrm{q}}$ pathway. Retinal growth cone collapse induced by $1 \mu \mathrm{M}$ LPA or S1P in the presence of PLC inhibitor U-73122 or calcium chelation by BAPTA compared to the control (without inhibitor) or inhibitors alone. ${ }^{\mathrm{a}} \mathrm{p}<$ 0.0001 compared to the control (with or without inhibitor).

with no inhibitor. This result suggests that there is a partial role for the $\mathrm{G}_{\mathrm{i} / \mathrm{o}}$ signaling pathway in the LPA- and S1P-mediated growth cone collapse of embryonic chick retinal neurons.

In the Xenopus visual system, Campbell and Holt [21] found a role for $\mathrm{p} 38$, but not $\mathrm{p} 42 / 44$, MAPK in LPAinduced growth cone collapse. To investigate the role of MAPK in embryonic chick retinal growth cone collapse, we analyzed the effect of the p38 and p42/44 inhibitors that they used (SB 203580 and PD 98059, respectively) [21]. Similar to the Xenopus system, pretreatment with SB 203580 prevented LPA-induced growth cone collapse (fig. 7), suggesting a requirement for p38 activity. Blockage of p42/44 activity with PD 98059, however, had no effect on LPA-induced growth cone collapse, suggesting that the chick also does not require p42/44 activity, similar to Xenopus. However, when examining the growth cone collapse induced by S1P, a different response was observed. Neither pretreatment with SB 203580 nor pretreatment with PD 98059 blocked S1P-induced growth cone collapse (fig. 7), suggesting that neither p38 nor p42/44 activity is required for the S1P-mediated growth cone collapse of embryonic chick retinal neurons.

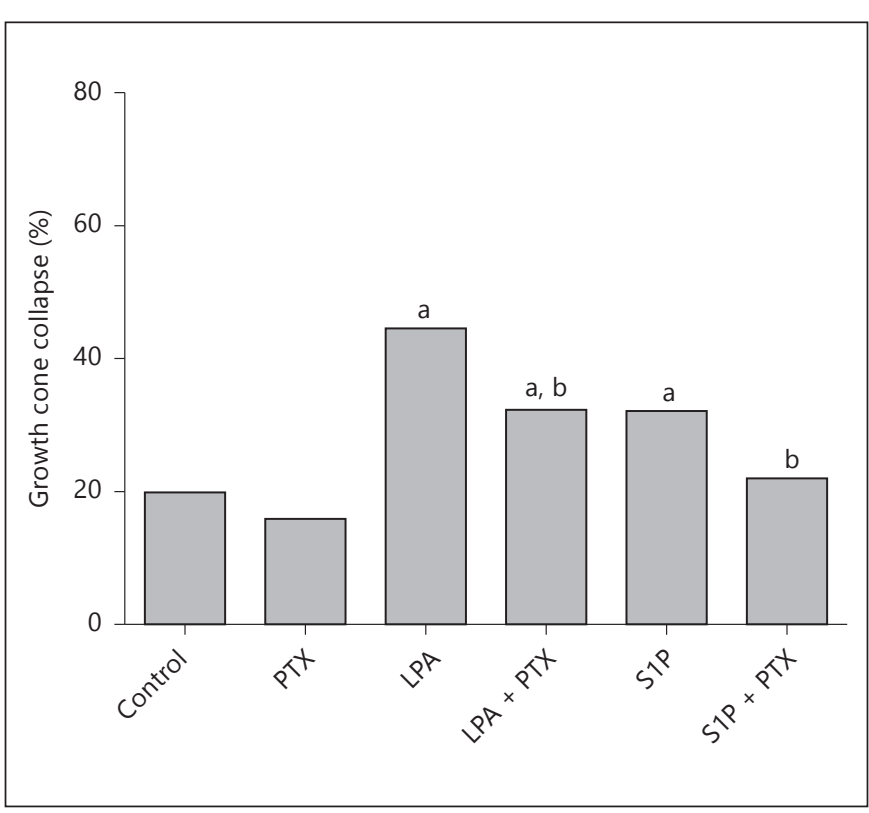

Fig. 6. Growth cone collapse blocking $\mathrm{G}_{\mathrm{i} / \mathrm{o}}$ by PTX. Retinal growth cone collapse induced by $1 \mu \mathrm{M}$ LPA or S1P in the presence of PTX compared to the control (without inhibitor) or PTX alone. ${ }^{\mathrm{a}} \mathrm{p}<$ 0.0001 compared to the control; ${ }^{\mathrm{b}} \mathrm{p}<0.0005$ compared to treatment with LPA or S1P without inhibitor.

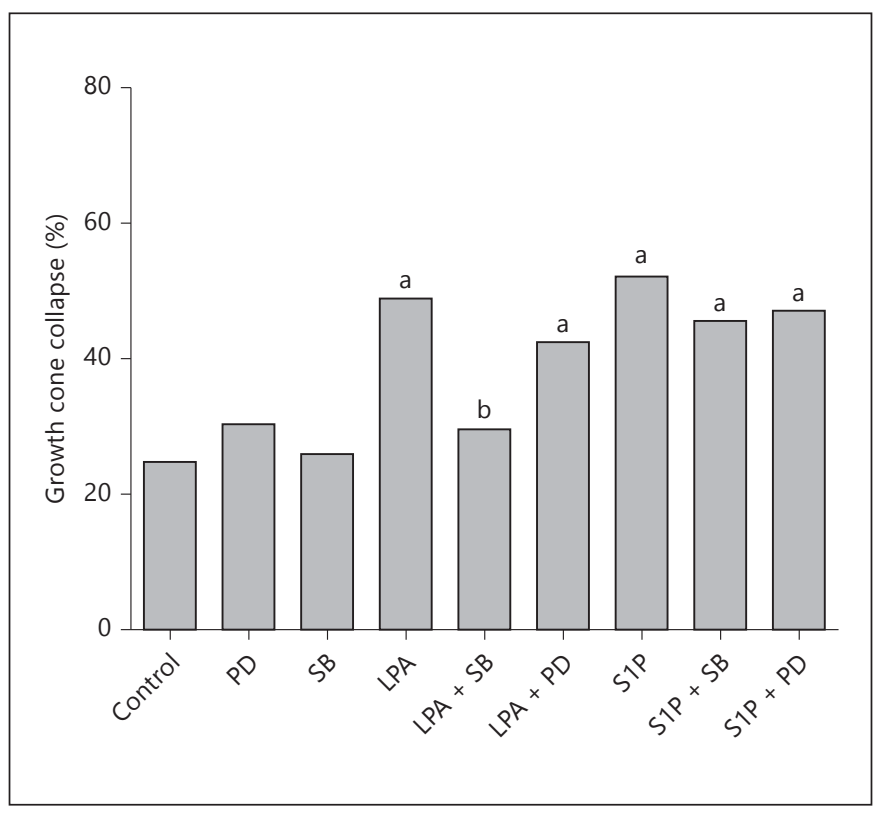

Fig. 7. Growth cone collapse with MAPK inhibitors. Retinal growth cone collapse induced by $1 \mu \mathrm{M}$ LPA or S1P in the presence of p38 inhibitor SB 203580 (SB) and p42/44 inhibitor PD 98059 (PD) compared to the control (without inhibitor) or inhibitors alone. ${ }^{\mathrm{a}} \mathrm{p}<0.0001$ compared to the control; ${ }^{\mathrm{b}} \mathrm{p}<0.0001$ compared to treatment with LPA without inhibitor. 


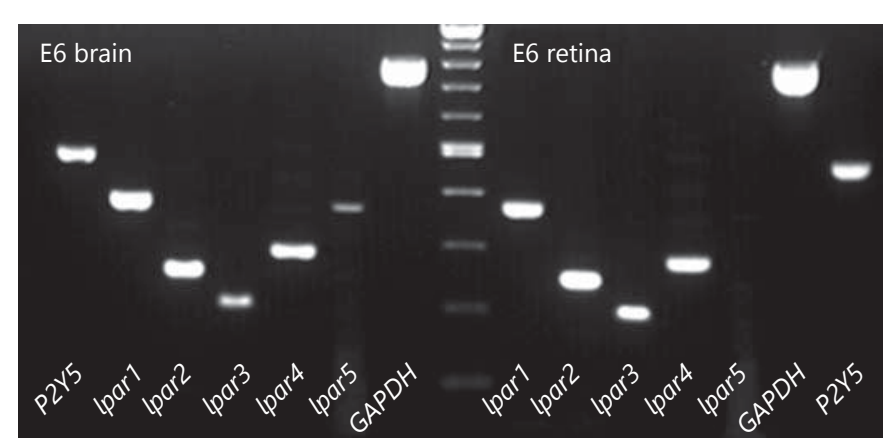

Fig. 8. Lpar gene expression in an E6 chick retina by RT-PCR. RTPCR expression of LPA receptor genes lpar1 to lpar5 as well as P2Y5 (lpar6) and the GAPDH control from E6 chick retina (right) compared to a brain control (left). Note the expression of all lpar genes except lpar5 in the retina compared to the expression of all genes in the brain. Controls without reverse transcription had no bands after PCR (data not shown). The center lane is a molecular weight marker.

\section{LPA Receptor Gene Expression}

In addition, we analyzed the LPA receptor gene expression in developing chick retina by RT-PCR. Expression for lpar1, lpar2, lpar3, and lpar4 was detected in E6 retina, but lpar5 mRNA was not detected in retina, as shown in the sample gel in figure 8 . In addition, the lowaffinity LPA receptor P2Y5, also referred to as lpar6 [28], was expressed in chick retina. All genes were detected in E6 chick brain samples (fig. 8), which were used as an expression control. Similar results were seen in chick RNA samples from E5 to E12 (data not shown).

\section{Discussion}

We have established that LPA and S1P cause a specific, dose-dependent growth cone collapse of embryonic chicken retinal neurites in vitro. Furthermore, we analyzed the intracellular signaling pathways mediating this growth cone collapse. Chelation of calcium with BAPTA or inhibition of PLC with U-73122 did not prevent LPAor S1P-mediated growth cone collapse, leading us to conclude that the $G_{\mathrm{q}}$ intracellular signaling pathway is not used by LPA and S1P to cause the cytoskeletal rearrangements that are involved in growth cone collapse. However, blocking ROCK with either Y-27632 or H1152 downstream of $\mathrm{G}_{12 / 13}$ and rho did prevent growth cone collapse both by LPA and by S1P. This is not surprising as rho and ROCK have been shown to mediate cytoskeletal retraction [36, 37], including growth cone collapse

Chick Retinal Growth Cone Signaling by LPA and S1P
$[17,38-40]$. Furthermore, in neuroblastoma cells as well as PC12 cell lines, blocking rho or ROCK inhibited LPAas well as S1P-mediated neurite retraction $[11,12,41]$. Thus, as in other systems, the $\mathrm{G}_{12 / 13}$-rho-ROCK pathway is required for LPA- and S1P-induced growth cone collapse of chick retinal axons.

Interestingly, blocking the $\mathrm{G}_{\mathrm{i} / \mathrm{o}}$ pathway with PTX treatment reduced, but did not eliminate, the growth cone collapse induced by LPA and S1P. Thus, there may be a role for the $G_{i / o}$ pathway in modulating growth cone collapse, possibly in some growth cones but not in others. This result could be consistent with other investigations, as it has been reported that LPA-induced neurite retraction in PC12 cells is independent of PTX treatment [12]. However, other reports have shown that PTX treatment does block growth cone collapse [4247]. Exactly why PTX blocks growth cone collapse in some retinal growth cones but not in others requires further investigation. It is well known that cAMP levels can influence whether a particular axon guidance molecule is attractive or repulsive [48-50], so there may be a heterogeneity of baseline cAMP levels in our cultures such that blocking $\mathrm{G}_{\mathrm{i} / \mathrm{o}}$ before LPA or S1P treatment would have different effects. Furthermore, the $\mathrm{G}_{\mathrm{i} / \mathrm{o}}$ pathway is known to activate rac, which has been shown to be involved in cytoskeletal protrusion and growth cone extension as well as neurite growth $[13,51]$. Thus, blocking $G_{i / o}$ could influence rac activation, which could be involved in mediation of the cytoskeletal rearrangements we see as growth cone collapse. However, if LPA and S1P normally activate $\mathrm{G}_{\mathrm{i} / \mathrm{o}}$ and rac, this activation would likely not lead to growth cone collapse but rather to extension; thus, when $G_{i / o}$ is blocked, one might expect more, not less, growth cone collapse. However, as cytoskeletal dynamics are critical for growth cone extension, blocking $\mathrm{G}_{\mathrm{i} / \mathrm{o}}$ and influencing the levels of rac activation could cause other effects on growth cone motility. Interestingly, other reports have suggested an interplay between rac and rho that is blocked by PTX $[46,47]$. Furthermore, recent reports suggest that growth cone collapse can be modulated by a noncanonical $\mathrm{G}_{\mathrm{i} / \mathrm{o}}$ pathway. The chemokine SDF-1 reduced, but did not block, the slit-2-induced growth cone collapse of chick retinal neurons through the receptor CXCR4, thus acting as a modulator of the growth cone collapse response [52]. Signaling by SDF-1 led to increased cAMP levels [52] and required $G_{\alpha i}, G_{\alpha q}$, and $\mathrm{G}_{\beta \gamma}$ [53]. PTX blocked SDF-1 modulation, but by a noncanonical pathway as SDF-1 signaling led to an increase in cAMP and not a decrease as in the canonical $\mathrm{G}_{\alpha i}$ sig- 
naling $[52,53]$. Overall, this partial involvement of $\mathrm{G}_{\mathrm{i} / \mathrm{o}}$ or reduction of LPA- and S1P-mediated growth cone collapse is interesting and warrants further study.

We note that the results we obtained on embryonic chick retinal axons are very similar to previous reports on Xenopus [20-22]. Our baseline growth cone collapse of chick retinal neurons of about $20 \%$ is similar to that reported in Xenopus, and a maximal growth cone collapse of about $60 \%$ is similar to the $50-60 \%$ reported for LPA and S1P in Xenopus [22]. We also examined the requirement for p42/p44 and p38 signaling in LPA- and S1Pmediated growth cone collapse compared to Xenopus. In Xenopus, Campbell and Holt [21] showed that the LPA-induced growth cone collapse of retinal growth cones could be blocked by p38 inhibitors but not by p $42 /$ p44 inhibitors. In our experiments on chick retinal neurites, the p38 inhibitor SB 203580 also blocked growth cone collapse by LPA, but not the p42/44 inhibitor PD 98059, similar to Xenopus. Thus, this pathway for LPAinduced growth cone collapse appears to be conserved between the chick and the frog. Interestingly, neither the p38 inhibitor SB 203580 nor the p42/44 inhibitor PD 98059 blocked the growth cone collapse of chick retinal neurites induced by S1P. Thus, it appears that S1P-induced growth cone collapse proceeds via a slightly different mechanism, although it still has other similarities with LPA-induced growth cone collapse, such as the requirement for ROCK.

In comparison to the mouse system, we note some differences between this current study on the chick and our previous study on the mouse [19]. First, in the chick, both LPA and S1P cause retinal growth cone collapse, while in the mouse, only LPA (and not S1P) causes retinal growth cone collapse. Second, in the chick, the percentage of retinal growth cone collapse did not reach $100 \%$ as it did in the mouse. Time-lapse imaging analysis of chick retinal neurites suggests that there is only a very small percentage of growth cones that do not respond to LPA (data not shown). However, in the chick there appears to be a relatively rapid desensitization to LPA, as growth cones reemerge and neurites begin to extend again (within 20-30 min). Because of this regrowth, we used a 10-min treatment for LPA and S1P in our growth cone collapse assay. This 10-min treatment allowed us to see the majority of the collapsed growth cones, although some growth cones may have reextended while others may not have collapsed yet, resulting in a lower, but still significant, growth cone collapse response. Thus, there are some interesting species differences between the chick and the mouse.

\section{Lysophospholipids and Axon Guidance}

What are the in vivo roles for LPA and S1P for retinal axons? Could they be involved in axon guidance? This work and others have demonstrated that the lysophospholipids LPA and S1P cause growth cone collapse in a variety of cell types, including RGCs [16, 19, 22]. Growth cone collapse is a hallmark of an inhibitory axon guidance cue. Indeed, one of the original growth cone-collapsing factors, i.e. collapsin, now known as semaphorin III $[8,9$, 54-58], was identified based on its growth cone-collapsing function and was subsequently shown to be involved in axon guidance in vivo [56-58]. Several other bona fide inhibitory axon guidance cues, including slit $[5,7,59]$ and the ephrins [1,60-68], have been shown to possess growth cone collapse activity. The in vitro growth cone collapse assay obviously differs from the in vivo situation in that the collapsing agent is added uniformly around the growth cone. It is thought that in vivo the collapsing agent would be directional, causing the growth cone to 'collapse' or be inhibited on one side and then turn in the opposite direction [69]. Thus, growth cone collapse activity can imply inhibitory axon guidance function, suggesting that LPA and S1P may act as axon guidance cues; however, true axon guidance activity would need to be confirmed in vivo to establish this role.

What could be the possible roles for LPA and S1P in the visual system? RGC axonal growth cones navigate a defined pathway, with multiple guidance decisions made along the way $[70,71]$, as well as specificity at the target for formation of a topographic map. The potential role of LPA and/or S1P in this pathway is currently not known. In Xenopus, S1P or a sphinogosine kinase inhibitor affected the growth of RGC axons into the tectum [22], suggesting that S1P may be involved in mediating RGC axon entry into the tectum. Furthermore, autotaxin, a major enzyme responsible for LPA production, is expressed strongly in caudal diencephalon $[72,73]$, suggesting that LPA could be responsible for preventing RGC axon growth beyond the tectum. There is also the possibility that LPA and/or S1P may be involved in topographic mapping of RGC axons to the tectum, although preliminary evidence suggests that this may not be the case. Analysis of our chick retinal explants taken from all regions of the retina did not show a bimodal distribution of the response to LPA or S1P (data not shown). If LPA and/or S1P is involved in topographic mapping, one might expect some explants from one part of the retina to show growth cone collapse and other explants from a different retinal region not to show growth cone collapse, and this was not apparent from our data. Furthermore, a preliminary analysis of responses from ret- 
inal explants from different quadrants to LPA and S1P did not show any major differences in growth cone collapse. For instance, there was no significant difference in growth cone collapse from nasal explants compared to temporal explants with either LPA or S1P. However, these results are preliminary and further analysis is warranted.

Another aspect of LPA and S1P as potential axon guidance molecules is the requirement of receptors on the responding cells. LPA and S1P bind to and activate a set of GPCRs. There are at least 5 receptors for LPA $[25,26]$, with others likely, including P2Y5 $[27,28]$, and at least 5 receptors for S1P $[25,26]$. Using RT-PCR, we have shown that the LPA receptor genes lpar1, lpar2, lpar3, lpar4, and p2y5, but not lpar5, are expressed in developing chick retina. Furthermore, the S1P receptor genes s1p1r and $s 1 p 3 r$ are also expressed in developing chick retina [unpubl. data]. Thus, LPA and S1P receptors are expressed in the appropriate tissue to act as retinal axon guidance factors, although definitive expression in RGCs and their growth cones requires further analysis.
In summary, we have shown that the lysophospholipids LPA and S1P are inhibitory for embryonic chick retinal growth cones in vitro, causing growth cone collapse. This growth cone collapse is mediated by classic $\mathrm{G}_{12 / 13}$-rho-ROCK signaling. In addition, there is an involvement of $G_{i / o}$, although this is a partial requirement. These responses are similar to previous reports in the mouse and Xenopus, but with some minor differences. This growth cone collapse is suggestive of a potential axon guidance role of lysophospholipids in the visual system.

\section{Acknowledgements}

We thank the Tyson Farms Complex of Monroe, N.C., USA, for providing chicken eggs. This work was supported by grants from Winthrop University and by NIH grant No. P20 RR-16461 from the National Center for Research Resources in support of the program entitled South Carolina IDeA Networks of Biomedical Research Excellence (SC-INBRE).

\section{References}

1 Feldheim DA, O'Leary DD: Visual map development: bidirectional signaling, bifunctional guidance molecules, and competition. Cold Spring Harb Perspect Biol 2010; 2:a001768.

$>2$ Deiner MS, Kennedy TE, Fazeli A, Serafini T, Tessier-Lavigne M, Sretavan DW: Netrin-1 and DCC mediate axon guidance locally at the optic disc: loss of function leads to optic nerve hypoplasia. Neuron 1997;19:575-589.

$\checkmark 3$ Deiner MS, Sretavan DW: Altered midline axon pathways and ectopic neurons in the developing hypothalamus of netrin-1- and DCC-deficient mice. J Neurosci 1999;19: 9900-9912.

4 Erskine L, Williams SE, Brose K, Kidd T, Rachel RA, Goodman CS, Tessier-Lavigne M, Mason CA: Retinal ganglion cell axon guidance in the mouse optic chiasm: expression and function of robos and slits. J Neurosci 2000;20:4975-4982.

$\checkmark 5$ Niclou SP, Jia L, Raper JA: Slit2 is a repellent for retinal ganglion cell axons. J Neurosci 2000;20:4962-4974.

6 Ringstedt T, Braisted JE, Brose K, Kidd T, Goodman C, Tessier-Lavigne M, O'Leary DDM: Slit inhibition of retinal axon growth and its role in retinal axon pathfinding and innervation patterns in the diencephalon. J Neurosci 2000;20:4983-4991.

>7 Plump AS, Erskine L, Sabatier C, Brose K, Epstein CJ, Goodman CS, Mason CA, TessierLavigne M: Slit1 and Slit2 cooperate to prevent premature midline crossing of retinal axons in the mouse visual system. Neuron 2002;33:219-232.

-8 Oster SF, Bodeker MO, He F, Sretavan DW: Invariant Sema5A inhibition serves an ensheathing function during optic nerve development. Development 2003;130:775784.

$>9$ Campbell DS, Regan AG, Lopez JS, Tannahill D, Harris WA, Holt CE: Semaphorin 3A elicits stage-dependent collapse, turning, and branching in Xenopus retinal growth cones. J Neurosci 2001;21:8538-8547.

10 Jalink K, Eichholtz T, Postma FR, van Corven EJ, Moolenaar WH: Lysophosphatidic acid induces neuronal shape changes via a novel, receptor-mediated signaling pathway: similarity to thrombin action. Cell Growth Differ 1993;4:247-255.

-11 Jalink K, van Corven EJ, Hengeveld T, Morii N, Narumiya S, Moolenaar WH: Inhibition of lysophosphatidate- and thrombin-induced neurite retraction and neuronal cell rounding by ADP ribosylation of the small GTP-binding protein Rho. J Cell Biol 1994; 126:801-810

12 Tigyi G, Fischer DJ, Sebok A, Marshall F, Dyer DL, Miledi R: Lysophosphatidic acid-induced neurite retraction in PC12 cells: neurite- protective effects of cyclic AMP signaling. J Neurochem 1996;66:549-558.

13 Kozma R, Sarner S, Ahmed S, Lim L: Rho family GTPases and neuronal growth cone remodelling: relationship between increased complexity induced by $\mathrm{Cdc} 42 \mathrm{Hs}$, Rac1, and acetylcholine and collapse induced by RhoA and lysophosphatidic acid. Mol Cell Biol 1997; 17:1201-1211.

14 Sato K, Tomura H, Igarashi Y, Ui M, Okajima F: Exogenous sphingosine 1-phosphate induces neurite retraction possibly through a cell surface receptor in PC12 cells. Biochem Biophys Res Commun 1997;240:329-334.

-15 MacLennan AJ, Devlin BK, Marks L, Gaskin AA, Neitzel KL, Lee N: Antisense studies in PC12 cells suggest a role for $\mathrm{H} 218$, a sphingosine 1-phosphate receptor, in growth-factor-induced cell-cell interaction and neurite outgrowth. Dev Neurosci 2000; 22:283-295.

16 Saito S: Effects of lysophosphatidic acid on primary cultured chick neurons. Neurosci Lett 1997;229:73-76.

-17 Bito H, Furuyashiki T, Ishihara H, Shibasaki Y, Ohashi K, Mizuno K, Maekawa M, Ishizaki T, Narumiya S: A critical role for a Rho-associated kinase, p160ROCK, in determining axon outgrowth in mammalian CNS neurons. Neuron 2000;26:431-441.

18 Zhang XF, Schaefer AW, Burnette DT, Schoonderwoert VT, Forscher P: Rho-dependent contractile responses in the neuronal growth cone are independent of classical peripheral retrograde actin flow. Neuron 2003; 40:931-944.

19 Birgbauer E, Chun J: Lysophospholipid receptors $\mathrm{LPA}_{1-3}$ are not required for the inhibitory effects of LPA on mouse retinal growth cones. Eye Brain 2010;2010:1-13. 
20 Campbell DS, Holt CE: Chemotropic responses of retinal growth cones mediated by rapid local protein synthesis and degradation. Neuron 2001;32:1013-1026.

21 Campbell DS, Holt CE: Apoptotic pathway and MAPKs differentially regulate chemotropic responses of retinal growth cones. Neuron 2003;37:939-952.

-22 Strochlic L, Dwivedy A, van Horck FP, Falk J, Holt CE: A role for S1P signalling in axon guidance in the Xenopus visual system. Development 2008;135:333-342.

23 Anliker B, Chun J: Lysophospholipid G protein-coupled receptors. J Biol Chem 2004;279: 20555-20558.

24 Birgbauer E, Chun J: New developments in the biological functions of lysophospholipids. Cell Mol Life Sci 2006;63:2695-2701.

25 Chun J, Goetzl EJ, Hla T, Igarashi Y, Lynch KR, Moolenaar W, Pyne S, Tigyi G: International Union of Pharmacology. 34. Lysophospholipid receptor nomenclature. Pharmacol Rev 2002;54:265-269.

-26 Chun J, Hla T, Lynch KR, Spiegel S, Moolenaar WH: International Union of Basic and Clinical Pharmacology. 77. Lysophospholipid receptor nomenclature. Pharmacol Rev 2010; 62:579-587.

27 Pasternack SM, von Kugelgen I, Aboud KA, Lee YA, Ruschendorf F, Voss K, Hillmer AM, Molderings GJ, Franz T, Ramirez A, Nurnberg P, Nothen MM, Betz RC: G protein-coupled receptor P2Y5 and its ligand LPA are involved in maintenance of human hair growth. Nat Genet 2008;40:329-334.

-28 Yanagida K, Masago K, Nakanishi H, Kihara Y, Hamano F, Tajima Y, Taguchi R, Shimizu $\mathrm{T}$, Ishii S: Identification and characterization of a novel lysophosphatidic acid receptor, p2y5/LPA6. J Biol Chem 2009;284:1773117741.

-29 Tabata K, Baba K, Shiraishi A, Ito M, Fujita N: The orphan GPCR GPR87 was deorphanized and shown to be a lysophosphatidic acid receptor. Biochem Biophys Res Commun 2007; 363:861-866.

- 30 Murakami M, Shiraishi A, Tabata K, Fujita $\mathrm{N}$ : Identification of the orphan GPCR, $\mathrm{P} 2 \mathrm{Y}(10)$ receptor as the sphingosine-1-phosphate and lysophosphatidic acid receptor. Biochem Biophys Res Commun 2008;371: 707-712.

-31 Katada T, Ui M: Slow interaction of islet-activating protein with pancreatic islets during primary culture to cause reversal of alpha-adrenergic inhibition of insulin secretion. J Biol Chem 1980;255:9580-9588.

- 32 Katada T, Amano T, Ui M: Modulation by islet-activating protein of adenylate cyclase activity in C6 glioma cells. J Biol Chem 1982; 257:3739-3746.

33 Kaslow HR, Burns DL: Pertussis toxin and target eukaryotic cells: binding, entry, and activation. FASEB J 1992;6:2684-2690.

-34 Yanagida K, Ishii S, Hamano F, Noguchi K, Shimizu T: LPA4/p2y9/GPR23 mediates rhodependent morphological changes in a rat neuronal cell line. J Biol Chem 2007;282: 5814-5824

35 Tigyi G, Fischer DJ, Sebok A, Yang C, Dyer DL, Miledi R: Lysophosphatidic acid-induced neurite retraction in PC12 cells: control by phosphoinositide- $\mathrm{Ca}^{2+}$ signaling and Rho. J Neurochem 1996;66:537-548.

-36 Ridley AJ, Hall A: The small GTP-binding protein rho regulates the assembly of focal adhesions and actin stress fibers in response to growth factors. Cell 1992;70:389-399.

- 37 Etienne-Manneville S, Hall A: Rho GTPases in cell biology. Nature 2002;420:629-635.

38 Kuhn TB, Brown MD, Wilcox CL, Raper JA, Bamburg JR: Myelin and collapsin-1 induce motor neuron growth cone collapse through different pathways: inhibition of collapse by opposing mutants of rac1. J Neurosci 1999; 19: 1965-1975.

39 Luo L: Rho GTPases in neuronal morphogenesis. Nat Rev Neurosci 2000;1:173-180.

40 Jin Z, Strittmatter SM: Rac1 mediates collapsin-1-induced growth cone collapse. J Neurosci 1997; 17:6256-6263.

41 Postma FR, Jalink K, Hengeveld T, Moolenaar WH: Sphingosine-1-phosphate rapidly induces Rho-dependent neurite retraction: action through a specific cell surface receptor. EMBO J 1996;15:2388-2392.

42 Bates CA, Meyer RL: Heterotrimeric G protein activation rapidly inhibits outgrowth of optic axons from adult and embryonic mouse, and goldfish retinal explants. Brain Res 1996; 714:65-75.

43 Clark GD, Zorumski CF, McNeil RS, Happel LT, Ovella T, McGuire S, Bix GJ, Swann JW: Neuronal platelet-activating factor receptor signal transduction involves a pertussis toxinsensitive G-protein. Neurochem Res 2000;25: 603-611.

44 Goshima Y, Kawakami T, Hori H, Sugiyama Y, Takasawa S, Hashimoto Y, KagoshimaMaezono M, Takenaka T, Misu Y, Strittmatter SM: A novel action of collapsin: collapsin-1 increases antero- and retrograde axoplasmic transport independently of growth cone collapse. J Neurobiol 1997;33:316-328.

45 Nakayama T, Goshima Y, Misu Y, Kato T: Role of cdk5 and tau phosphorylation in heterotrimeric $G$ protein-mediated retinal growth cone collapse. J Neurobiol 1999;41:326-339.

-46 Sato K, Horiuchi Y, Jin Y, Malchinkhuu E, Komachi M, Kondo T, Okajima F: Unmasking of LPA1 receptor-mediated migration response to lysophosphatidic acid by interleukin-1beta-induced attenuation of Rho signaling pathways in rat astrocytes. J Neurochem 2011;117:164-174.

47 Van Leeuwen FN, Olivo C, Grivell S, Giepmans BN, Collard JG, Moolenaar WH: Rac activation by lysophosphatidic acid LPA1 receptors through the guanine nucleotide exchange factor Tiam1. J Biol Chem 2003;278:400-406.

48 Ming GL, Song HJ, Berninger B, Holt CE, Tessier-Lavigne M, Poo MM: cAMP-dependent growth cone guidance by netrin-1. Neuron 1997;19:1225-1235.
49 Song H, Ming G, He Z, Lehmann M, TessierLavigne M, Poo MM: Conversion of neuronal growth cone responses from repulsion to attraction by cyclic nucleotides. Science 1998; 281:1515-1518.

50 Hopker VH, Shewan D, Tessier-Lavigne M, Poo MM, Holt C: Growth-cone attraction to netrin-1 is converted to repulsion by laminin1. Nature 1999;401:69-73.

51 de Curtis I: Functions of Rac GTPases during neuronal development. Dev Neurosci 2008; 30:47-58.

52 Chalasani SH, Sabelko KA, Sunshine MJ, Littman DR, Raper JA: A chemokine, SDF-1, reduces the effectiveness of multiple axonal repellents and is required for normal axon pathfinding. J Neurosci 2003;23:1360-1371.

53 Twery EN, Raper JA: SDF1-induced antagonism of axonal repulsion requires multiple Gprotein coupled signaling components that work in parallel. PLoS One 2011;6:e18896.

54 Luo Y, Raible D, Raper JA: Collapsin: a protein in brain that induces the collapse and paralysis of neuronal growth cones. Cell 1993; 75:217-227.

55 Raper JA, Kapfhammer JP: The enrichment of a neuronal growth cone collapsing activity from embryonic chick brain. Neuron 1990;2: 21-29.

56 Behar O, Golden JA, Mashimo H, Schoen FJ, Fishman MC: Semaphorin III is needed for normal patterning and growth of nerves, bones and heart. Nature 1996;383: 525-528.

57 Taniguchi M, Yuasa S, Fujisawa H, Naruse I, Saga S, Mishina M, Yagi T: Disruption of semaphorin III/D gene causes severe abnormality in peripheral nerve projection. Neuron 1997; 19:519-530.

58 Ulupinar E, Datwani A, Behar O, Fujisawa H, Erzurumlu R: Role of semaphorin III in the developing rodent trigeminal system. Mol Cell Neurosci 1999;13:281-292.

59 Bagri A, Marin O, Plump AS, Mak J, Pleasure SJ, Rubenstein JL, Tessier-Lavigne M: Slit proteins prevent midline crossing and determine the dorsoventral position of major axonal pathways in the mammalian forebrain. Neuron 2002;33:233-248.

60 Drescher U, Kremoser C, Handwerker C, Loschinger J, Noda M, Bonhoeffer F: In vitro guidance of retinal ganglion cell axons by RAGS, a $25 \mathrm{kDa}$ tectal protein related to ligands for Eph receptor tyrosine kinases. Cell 1995;82:359-370.

61 Brennan C, Monschau B, Lindberg R, Guthrie B, Drescher U, Bonhoeffer F, Holder N: Two Eph receptor tyrosine kinase ligands control axon growth and may be involved in the creation of the retinotectal map in the zebrafish. Development 1997;124:655-664.

62 Meima L, Kljavin IJ, Moran P, Shih A, Winslow JW, Caras IW: AL-1-induced growth cone collapse of rat cortical neurons is correlated with REK7 expression and rearrangement of the actin cytoskeleton. Eur J Neurosci 1997;9:177-188. 
63 Meima L, Moran P, Matthews W, Caras IW: Lerk2 (ephrin-B1) is a collapsing factor for a subset of cortical growth cones and acts by a mechanism different from AL-1 (ephrin-A5). Mol Cell Neurosci 1997;9:314-328.

64 Davenport RW, Thies E, Zhou R, Nelson PG Cellular localization of ephrin-A2, ephrinA5, and other functional guidance cues underlies retinotopic development across species. J Neurosci 1998;18:975-986.

-65 Wahl S, Barth H, Ciossek T, Aktories K, Mueller BK: Ephrin-A5 induces collapse of growth cones by activating Rho and Rho kinase. J Cell Biol 2000;149:263-270.

-66 Frisén J, Yates PA, McLaughlin T, Friedman GC, O’Leary DDM, Barbacid M: Ephrin-A5 (AL-1/RAGS) is essential for proper retinal axon guidance and topographic mapping in the mammalian visual system. Neuron 1998; 20:235-243.
67 Feldheim DA, Kim YI, Bergemann AD, Frisen J, Barbacid M, Flanagan JG: Genetic analysis of ephrin-A2 and ephrin-A5 shows their requirement in multiple aspects of retinocollicular mapping. Neuron 2000;25:563-574.

68 Pfeiffenberger C, Yamada J, Feldheim DA: Ephrin-As and patterned retinal activity act together in the development of topographic maps in the primary visual system. J Neurosci 2006;26:12873-12884.

69 Fan J, Raper JA: Localized collapsing cues can steer growth cones without inducing their full collapse. Neuron 1995;14:263-274.
70 Oster SF, Deiner M, Birgbauer E, Sretavan DW: Ganglion cell axon pathfinding in the retina and optic nerve. Semin Cell Dev Biol 2004; 15:125-136.

71 Erskine L, Herrera E: The retinal ganglion cell axon's journey: insights into molecular mechanisms of axon guidance. Dev Biol 2007;308: $1-14$.

72 Ohuchi H, Fukui H, Matsuyo A, Tomonari S, Tanaka M, Arai H, Noji S, Aoki J: Autotaxin controls caudal diencephalon-mesencephalon development in the chick. Dev Dyn 2010; 239:2647-2658.

73 Ohuchi H, Hayashibara Y, Matsuda H, Onoi M, Mitsumori M, Tanaka M, Aoki J, Arai H, Noji S: Diversified expression patterns of autotaxin, a gene for phospholipidgenerating enzyme during mouse and chicken development. Dev Dyn 2007;236: 1134-1143. 